\title{
Corrosion Behavior of Bismuth in Concentrated Sulphuric Acid Solution and Stability of its Surface Oxide Film
}

\author{
A.S. Mogoda ${ }^{1, *}$ and K. M. Zohdy ${ }^{2}$ \\ ${ }^{1}$ Chemistry Department, Faculty of Science, Cairo University, Giza 12613, Egypt \\ ${ }^{2}$ Higher Technology Institute, Tenth of Ramadan City, Egypt \\ *E-mail: awad_mogoda@hotmail.com
}

Received: 3 August 2021 / Accepted: 4 October 2021 / Published: 6 December 2021

\begin{abstract}
The surface activity of bismuth (Bi) was investigated in $4.97 \mathrm{M} \mathrm{H}_{2} \mathrm{SO}_{4}$ solution using cyclic voltammetry (CV), potentiodynamic polarization and electrochemical impedance spectroscopy (EIS) measurements. The $\mathrm{CV}$ results indicated that the current plateau values increase as the scan rate increases. This may be caused by the high ionic character of the protective film formed on Bi surface. From the EIS results it was found that the thickness of each of the pre-immersion oxide and the anodically formed film on Bi decreases with increasing of the immersion time due to their dissolution in the acid medium. Polarization scans showed that the rate of corrosion of $\mathrm{Bi}$ in the acid solution rises as the polarization temperature increases. The values of the thermodynamic parameters $\mathrm{E}_{\mathrm{a}}$ (activation energy), $\Delta \mathrm{H}$ (enthalpy change) and $\Delta \mathrm{S}$ (entropy change) of the corrosion process for $\mathrm{Bi}$ in the concentrated sulphuric acid solution were estimated. The surface of bismuth was demonstrated under scanning electron microscopy (SEM) after polishing and polarization in sulphuric acid as well as at the end of the EIS measurements (at $70 \mathrm{~min}$ ).
\end{abstract}

Keywords: Bismuth; cyclic voltammetry; EIS; polarization; SEM

\section{FULL TEXT}

(C) 2022 The Authors. Published by ESG (www.electrochemsci.org). This article is an open access article distributed under the terms and conditions of the Creative Commons Attribution license (http://creativecommons.org/licenses/by/4.0/). 